PPPL-3462

PPPL-3462

UC-70

Studies of Tritiated Co-deposited Layers in TFTR

by

C.H. Skinner, C.A. Gentile, G. Ascione, A. Carpe, R.A. Causey,

T. Hayashi, J. Hogan, S. Langish, M. Nishi, W.M. Shu, W.R. Wampler, and K. M. Young

June 2000

$\int D \sqrt{D} \int \sqrt{\zeta} \int\left[\begin{array}{l}\text { PAINCETON } \\ \text { PLABMA PHYSICS } \\ \text { LABOAATOAY }\end{array}\right.$

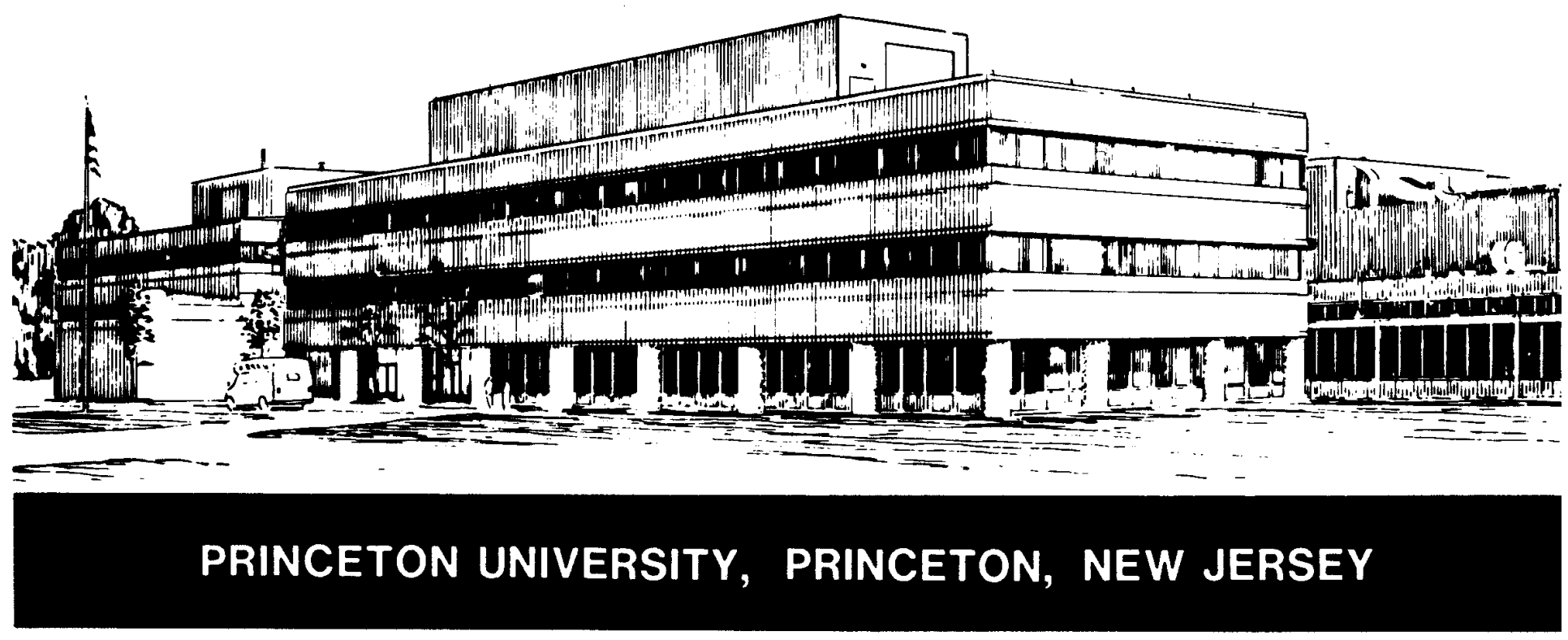




\section{PPPL Reports Disclaimer}

This report was prepared as an account of work sponsored by an agency of the United States Government. Neither the United States Government nor any agency thereof, nor any of their employees, makes any warranty, express or implied, or assumes any legal liability or responsibility for the accuracy, completeness, or usefulness of any information, apparatus, product, or process disclosed, or represents that its use would not infringe privately owned rights. Reference herein to any specific commercial product, process, or service by trade name, trademark, manufacturer, or otherwise, does not necessarily constitute or imply its endorsement, recommendation, or favoring by the United States Government or any agency thereof. The views and opinions of authors expressed herein do not necessarily state or reflect those of the United States Government or any agency thereof.

\section{Availability}

This report is posted on the U.S. Department of Energy's Princeton Plasma Physics Laboratory Publications and Reports web site in Calendar Year 2000. The home page for PPPL Reports and Publications is: http://www.pppl.gov/pub_report/

DOE and DOE Contractors can obtain copies of this report from:

U.S. Department of Energy

Office of Scientific and Technical Information

DOE Technical Information Services (DTIS)

P.O. Box 62

Oak Ridge, TN 37831

Telephone: (865) 576-8401

Fax: (865) 576-5728

Email: reports@adonis.osti.gov

This report is available to the general public from:

National Technical Information Service

U.S. Department of Commerce

5285 Port Royal Road

Springfield, VA 22161

Telephone: $1-800-553-6847$ or

(703) $605-6000$

Fax: (703) 321-8547

Internet: http://www.ntis.gov/ordering.htm 


\title{
Studies of Tritiated Co-deposited Layers in TFTR
}

\author{
C.H. Skinner, C.A. Gentile, G. Ascione, A. Carpe, R.A. Causey, ${ }^{a}$ T. Hayashi, ${ }^{\mathrm{d}}$

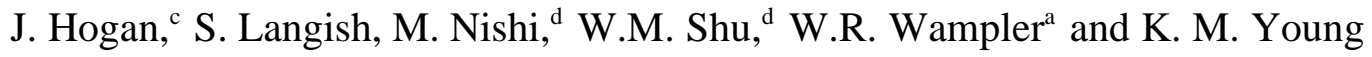 \\ Princeton Plasma Physics Laboratory, Princeton, New Jersey, 08543 USA \\ ${ }^{a}$ Sandia National Laboratories, Albuquerque NM 87175 and Livermore CA 94550 \\ ${ }^{c}$ Oak Ridge National Laboratory, Oak Ridge, TN 37830 \\ ${ }^{d}$ Tritium Engineering Laboratory, JAERI, Ibaraki, Japan
}

\begin{abstract}
:
Plasma facing components in TFTR contain an important record of plasma wall interactions in reactor grade DT plasmas. Tiles, flakes, wall coupons, a stainless steel shutter and dust samples have been retrieved from the TFTR vessel for analysis. Selected samples have been baked to release tritium and assay the tritium content. The in-vessel tritium inventory is estimated to be $0.56 \mathrm{~g}$ and is consistent with the in-vessel tritium inventory derived from the difference between tritium fueling and tritium exhaust. The distribution of tritium on the limiter and vessel wall showed complex patterns of co-deposition. Relatively high concentrations of tritium were found at the top and bottom of the bumper limiter, as predicted by earlier BBQ modeling.
\end{abstract}

Keywords: tritium retention, tritium co-deposition, flakes, dust, nuclear fusion.

\section{Introduction}

Tritium issues are central to the development of fusion power[1]. A significant milestone was reached when deuterium - tritium plasmas in TFTR and JET produced 10 and 16 MW of fusion power respectively[2,3]. Tritium was retained inside the vacuum vessel of both TFTR and JET principally by co-deposition with carbon eroded from plasma facing components[4,5]. Tritium operations on TFTR extended over 3.5 years with $5 \mathrm{~g}$ of tritium supplied to the plasma via neutral beam injection and gas puffs. Extensive deuterium fueled discharges were used to optimize the 
plasma conditions before tritium injection and the isotopic ratio of T/D fueling was 3\%. In TFTR the average tritium retention fraction was $51 \%$ during normal plasma operations and $16 \%$ over the long term including clean up periods[6,7]. Tritium was removed from the vessel by air ventilation and glow discharge cleaning during two maintenance periods and after the termination of plasma operations[8,9].

The analysis of plasma facing components from tokamaks that have been operated with tritium plasmas is uniquely valuable in understanding the behavior of tritium in these devices. TFTR operated with toroidal plasmas with a circular cross-section that were in contact with an inner toroidal 'bumper' limiter. The total area of the bumper limiter was $22 \mathrm{~m}^{2}$ and it is divided into 20 bays (labeled A-T) each composed of 24 rows of tiles, 4 tiles wide. Each bay is curved in both toroidal and poloidal directions and the midplane center extends out $4.6 \mathrm{~mm}$ from a true toroidal surface. The midplane tiles are $125 \mathrm{~mm}$ wide and $81 \mathrm{~mm}$ high. High heat flux areas are covered with Fiber Materials Inc. 4D coarse weave carbon fiber composite (CFC) tiles and Hercules 3-D fine weave CFC tiles and the remainder Union Carbide AXF-5Q isotropic graphite[10]. The outer vacuum vessel is 304 stainless steel and is protected by several groups of graphite tiles arranged poloidally. Tiles also protect high heat flux locations on the edge of RF antennas and outboard surfaces in the line of sight of the neutral heating beams.

The plasma facing surfaces portray a rich and spatially complex imprint of many years of TFTR plasma operations (Fig.1). The connection length of a field line launched from the limiter surface varies strongly with spatial position and controls the balance between erosion and codeposition[11]. In Fig. 1, co-deposition is visible in a diagonal band from the upper right to lower left of bay $\mathrm{K}$ and on the left side of the poloidal limiter tile at the floor. Co-deposited layers on graphite tiles began to flake after the termination of plasma operations[12,13]. Minor flaking can now be observed on CFC tiles and of co-deposited layers on the stainless steel vessel floor. The 
vessel has been activated by $14 \mathrm{MeV}$ DT neutrons and the dose rate inside the vessel is $\approx 34$ mrem/hour $(340 \mu \mathrm{Sv} / \mathrm{hr})$. The TFTR vacuum vessel has been opened several times to record the condition of the bumper limiter and to retrieve samples as part of a PPPL/JAERI collaboration on tritium issues. Some tiles were removed by specialized tools operated from outside the vessel, however it became clear that vessel entry was necessary to retrieve samples without disturbing their material surfaces. More importantly, vessel entry enabled rapid collection of samples and minimized personnel radiation exposure. Bubble suits with externally supplied air were employed in two entries into the vessel to retrieve tiles, flakes, wall coupons, a stainless steel shutter and dust samples and to make in-vessel measurements of surface tritium. Tests of a tritium imaging system are reported separately in these proceedings[14]. Decommissioning activities commenced in October 1999 and will extend over 3 years. In the year 2002, the vessel will be filled with low density cellular concrete, cut into ten segments by a $10 \mathrm{~mm}$ diamond wire rope and transported to a burial site[15].

\section{TFTR tritium inventory:}

Measurements of the tritium inventory of DT machines are important to verify compliance with regulatory safety limits during plasma operations and for end-of-life disposal. The tritium released from bakeout of selected tiles retrieved from the TFTR bumper limiter is shown in Fig.1. Tiles from column $\mathrm{C}$ were selected to provide a comparison to previous $\mathrm{D}$ measurements[16]. The tiles were typically baked at a temperature of $500 \mathrm{C}$ in air for 1 hour, a few tiles had preliminary bakes at 350 C. Previous measurements of TFTR tiles exposed to deuterium plasmas showed the majority of hydrogen isotope released on baking in air at $350 \mathrm{C}$ for an hour[17,18]. The exhaust accumulated in a tank and the tritium was measured to $0.1 \mathrm{Ci}$ accuracy with an ion chamber (Fempto-tech). A constant airflow at 40 torr provided an order of magnitude more oxygen than required to oxidize the co-deposits and the tritium release terminated well before the end of the 
bake time. One tile was baked at $500 \mathrm{C}$ a second time but did not release a measurable amount of tritium.

Previous ion beam measurements of Bay $\mathrm{N}$ column $\mathrm{C}$ tiles exposed to deuterium plasmas showed a marked up/down contrast in near surface areal deuterium density on the plasma facing tile surface and projections of the expected tritium inventory treated areas of low deposition and high deposition separately[16]. Such an up/down contrast is not evident in the present measurements (Fig. 1). Significant differences include the coarser spatial resolution (1 tile compared to the $1 \mathrm{~mm}$ square ion beam) and the inclusion of tritium deposited on the sides of the tiles in the bakeout measurements (previous measurements showed relatively high deuterium deposition on sides of tiles with low deuterium on the plasma facing surface). Also, the bumper limiter was realigned after the deuterium measurements and, of course, the detailed plasma exposure history was different. Tile to tile variations in the present measurements may be partly due to residual alignment differences, differences in the width of the gaps between the tiles and the presence of diagnostic penetrations. The degree of toroidal symmetry is important for decommissioning. Tiles from the same relative location (row 13 column C) at bays I, E, and D showed similar (within \pm 17\%) tritium release as the bay $\mathrm{K}$ row 13 column $\mathrm{C}$ tile.

Complete incineration measurements are planned to measure the small fraction of tritium expected to remain in deep traps after bakeout at 500 C. For the present, we conservatively assume that $90 \%$ of the tritium was released. We estimate the tritium inventory of the bumper limiter as follows. The total plasma facing area of the baked tiles is $0.30 \mathrm{~m}^{2}$ and the total tritium released $23.4 \mathrm{Ci}$. Including a $10 \%$ allowance for unreleased tritium, the areal density is $87 \mathrm{Ci} / \mathrm{m}^{2}$. Extrapolating to the $22 \mathrm{~m}^{2}$ area of the bumper limiter, we estimate the tritium inventory of the bumper limiter to be $1,900 \mathrm{Ci}$ or $0.2 \mathrm{~g}$. 
Tritium also accumulates by co-deposition on the outboard plasma facing components such as the poloidal limiter CFC tiles (BF Goodrich 2.5D staple knit weave), neutral beam armor tiles and on the stainless steel vessel wall (in contrast to JET and other machines which experience wall erosion). Previous deuterium measurements[19] indicated $41 \%$ of the total deuterium inventory to be on the vessel wall with factor-of-three toroidal variations in local deuterium areal density as measured on coupons[20]. We have retrieved two poloidal limiter tiles, 3 pairs of graphite coupons and a stainless steel shutter and have baked one tile and 3 coupons and the shutter (Table 1). The tritium released was trapped in a highly sensitive differential atmospheric tritium sampler[21] and assayed by scintillation counting to an accuracy $\leq 10 \%$. The coupons have a 6.5 $\mathrm{cm}^{2}$ plasma facing surface but parts of the sides are also exposed and accumulate some tritium. An effective area of $12.6 \mathrm{~cm}^{2}$ was derived from the area weighted by the surface tritium as measured by an ion chamber. The total outboard vessel area is estimated at $110 \mathrm{~m}^{2}$ [20]. The average (poloidal limiter tile +3 coupons + shutter) tritium released areal density is $29 \mathrm{Ci} / \mathrm{m}^{2}$. Including an allowance for $10 \%$ unreleased tritium the total is $32 \mathrm{Ci} / \mathrm{m} 2$. This is $37 \%$ of the areal tritium density on the bumper limiter but the total outboard area is $5 \mathrm{x}$ larger so $65 \%$ of the total tritium appears to be on the outboard side. We estimate $3,500 \mathrm{Ci}$ on the outboard side and a total tritium inventory of 5,400 $\mathrm{Ci}$ or $0.56 \mathrm{~g}$. The sparse spatial sampling, especially on the outboard side $(0.1 \%)$, adds significant uncertainty to this estimate. 
Table 1 Outboard tritium.

\begin{tabular}{lcc}
\hline & $\begin{array}{c}\text { tritium } \\
\text { released }(\mathrm{Ci})\end{array}$ & $\begin{array}{c}\text { areal density } \\
\left(\mathrm{Ci} / \mathrm{m}^{2}\right)\end{array}$ \\
\hline Bay O/N tile & 3.8 & 31 \\
$\begin{array}{l}\text { Bay H midplane } \\
\text { coupon }\end{array}$ & 0.035 & 24 \\
$\begin{array}{l}\text { Bay N bottom } \\
\text { coupon }\end{array}$ & 0.095 & 65 \\
$\begin{array}{l}\text { Bay P midplane } \\
\text { coupon }\end{array}$ & 0.024 & 16 \\
$\begin{array}{l}\text { Bay H shutter } \\
\text { (stainless steel) }\end{array}$ & 0.396 & 9 \\
\hline
\end{tabular}

Previous estimates of tritium inventory in the vessel were derived from the difference between the cumulative tritium fueling and exhaust, corrected for radioactive decay. On 3 May 2000 this difference inventory was $0.64 \mathrm{~g}$. The agreement between the measurements of components removed from the vessel and the inventory derived from the difference between tritium fueling and tritium exhaust is excellent considering the experimental uncertainties and is an encouraging validation of the difference inventory methodology.

\section{Surface tritium measurements}

Surface tritium was measured inside the vessel by an open wall ion chamber[22]. This technique, and others that detect betas emitted from radioactive decay, detects tritium only in the top micron due to the limited range of the betas in graphite. The detector area was $3.4 \mathrm{~cm}$ diameter, however in some cases this was reduced to 1.2 or $0.6 \mathrm{~cm}$ diameter to extend the dynamic range or to sample a 
small area. Near surface tritium has been depleted by glow discharge and ventilation after the termination of plasma operations. Fig. 2 shows the surface tritium on the outer vessel wall at bays G, H, J, L. Large variations can be seen reflecting the complex geometry of the in-vessel hardware. Spatially complex patterns were also observed on the bay $\mathrm{K}$ bumper limiter tiles retrieved from the vessel (average surface tritium: $138 \mu \mathrm{Ci} / \mathrm{cm}^{2}$ ), bay $\mathrm{O} / \mathrm{N}$ poloidal limiter (average: $130 \mu \mathrm{Ci} / \mathrm{cm}^{2}$ ), and bay $\mathrm{G}$ neutral beam duct (average: $83 \mu \mathrm{Ci} / \mathrm{cm}^{2}$ ). Fig. 3 shows the surface tritium concentration from the bay $\mathrm{K}$ centerline before and after bakeout. The up/down asymmetry in tritium remaining after the bakeout is consistent with the lower rows being an erosion region where the oxidation rate of the tritium implanted in the native carbon is slower[18] than in the upper co-deposition region. Further elemental analyses of the components and tests of detritiation by UV and laser surface heating are planned[23].

\section{Flakes and dust.}

The mobilizability of tritium is an important factor in safety analyses of future DT reactors. Observations of flaking of the TFTR limiter were reported in [12,13]. Dust generated by plasma operations is an emerging area of concern[24,25] as the longer biological half-life of tritiated graphite dust makes it significantly more hazardous than HTO (tritiated water)[26]. In 1992 'several kilograms' of particulate debris were vacuumed from the TFTR torus[27]. Video inspection in 1996 indicated debris levels were reduced, most likely due to tile realignment. Dust samples were collected from the bottom of ten vertical diagnostic pipes and from the vessel floor in 1996[28]. Additional samples were collected in the recent vessel entry with a hand vacuum cleaner fitted with a slotted nozzle and 0.2 micron pore size filter. Particles and debris were evident on the floor of the vessel including flake fragments and debris from a laser assisted lithium conditioning aerosol device 'DOLLOP'. Bay $\mathbf{J}$ was particularly dusty and collection from a $10 \mathrm{~cm}$ x $10 \mathrm{~cm}$ area yielded $0.46 \mathrm{~g}$. In contrast the bottom of a neutral beam duct yielded only $0.06 \mathrm{~g}$ 
from a $20 \mathrm{~cm}$ x $60 \mathrm{~cm}$ area. The gap between the bumper limiter and poloidal limiter, revealed by tile removal at Bay $\mathrm{K}$, yielded $0.07 \mathrm{~g}$. Estimation of the total dust inventory was not possible because of the highly non-uniform distribution. Diagnostics to confidently establish compliance with regulatory dust limits in next step devices remain problematic. The most critical need is the development of means to remove dust.

\section{Comparison to modeling results.}

Tritium is retained by atomic and molecular process as the edge plasma interacts with plasma facing components. Co-deposition rates for representative conditions in TFTR DT plasmas were modeled with the BBQ code and the results reported in $13^{\text {th }}$ PSI conference[29]. The calculations indicated that known erosion mechanisms and subsequent co-deposition were sufficient to account for the order of magnitude of retention. Based on the modeling results, a prediction was made that 'when detailed analysis of TFTR tiles from the tritium campaign is made significant concentrations of co-deposited tritium will be found near the upper and lower leading edges of the bumper limiter.' This pattern was not expected from previous deuterium measurements[16] or earlier modeling[11].

The observation of high tritium concentrations in the upper and lower row of bumper limiter tiles (Fig. 1) suggests that the BBQ model is on the right track. Fig. 4 compares the row averaged areal density of tritium (tritium released by bakeout / plasma facing area) to the effective sputtering yield in Fig. 3 (\#76528) of ref. [29]. The higher effective sputtering yield at high latitudes and prompt local redeposition leads to high co-deposition of tritium in these areas. The data is consistent with the existence of a considerable number of TFTR discharges with large $(\sim 10 \mathrm{~cm})$ radial decay length of $\mathrm{D}^{+}$flux due to inner wall recycling and large parallel diffusivity. More detailed reconciliation of the model and data would require explicit 3-D treatment of tile-tile variations and diagnostic penetrations and more detailed representation of the complex discharge history over 3.5 
years of TFTR DT operations (including startup/shutdown, disruptions and tritium cleanup). Overall, the fact that the modeling was able to suggest a priori some features which were not otherwise expected is encouraging.

\section{Acknowledgments}

We wish to acknowledge informative discussions with A.A. Haasz, D. Loesser, and the dedicated work of C. Bunting, L. Ciebiera, R. Hitchner, K. Isobe, Y. Iwai, T. Guttadora, Y. Kawamura, E. Kearns, D. Mueller, S. Palko, J. Parker, R. Planetta, D. Shaltis, W. Shu, E. Starkmann, R. Szaro, C. Tilson, W. Walker, T. Yamanishi. The encouragement and support of J. Hosea, A. von Halle, and S. Matsuda is gratefully acknowledged. Support is provided by the Annex IV to the JAERI/DOE Implementing Arrangement on Cooperation in Fusion Research and Development, U.S. DOE Contract Nos. DE-AC02-76CH03073 and DE-ACO4-94AL85000. 

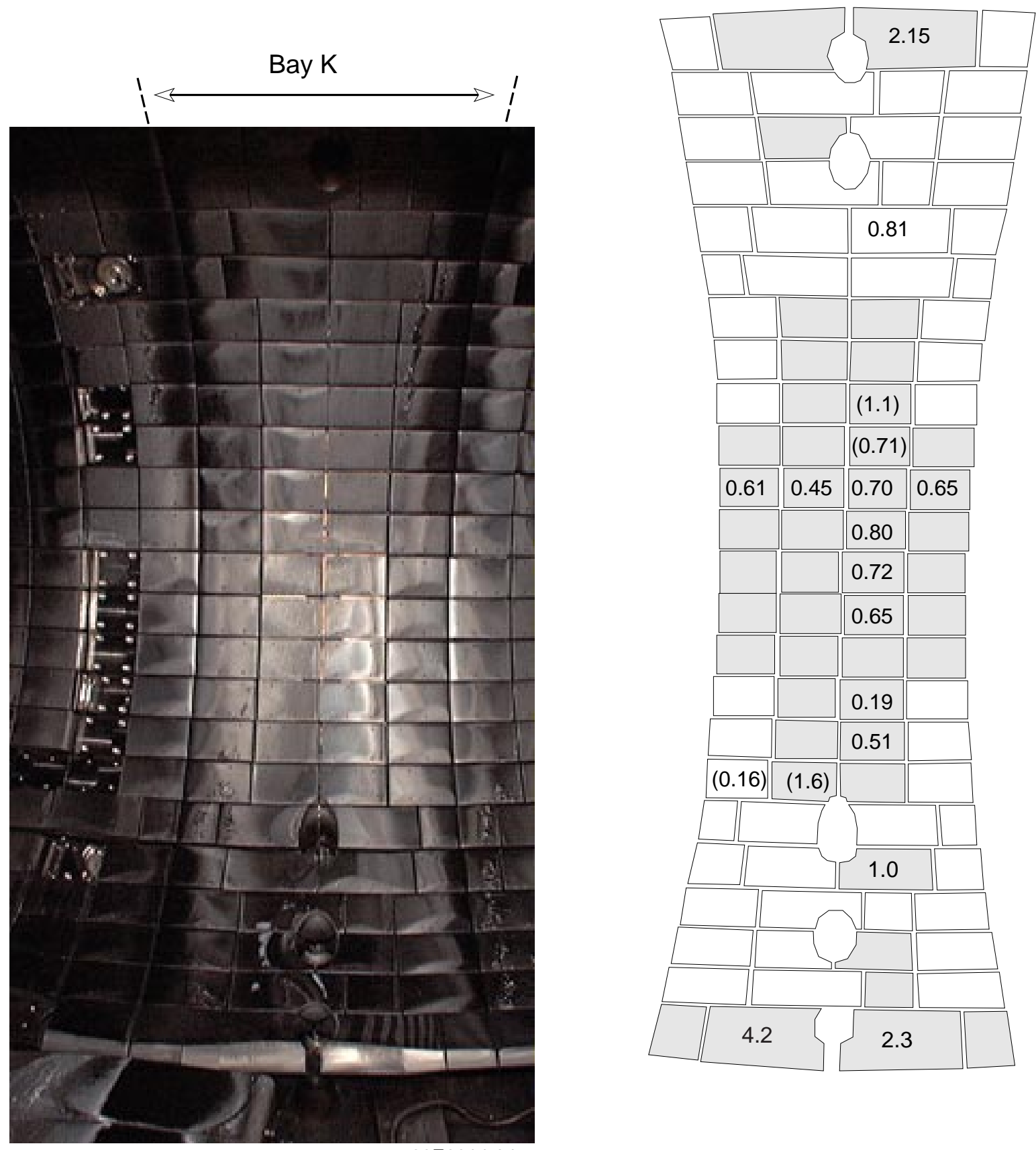

99E0014-04

Fig.1 TFTR bumper limiter at Bay K on $17^{\text {th }}$ February 1999 showing co-deposition, flaking and white deposits. Some tiles have been removed from Bay L on the left. Deposition on a poloidal limiter tile may be seen at the lower left. The tiles are numbered by row from 1 (bottom) to 24 (top) and by column left (A) to right (D). The diagram depicts the tritium released (in Curies) from baking selected Bay K tiles (in parentheses Bay L tiles). Unshaded tiles are AXF-5Q graphite, gray shading denotes carbon fiber composite. 


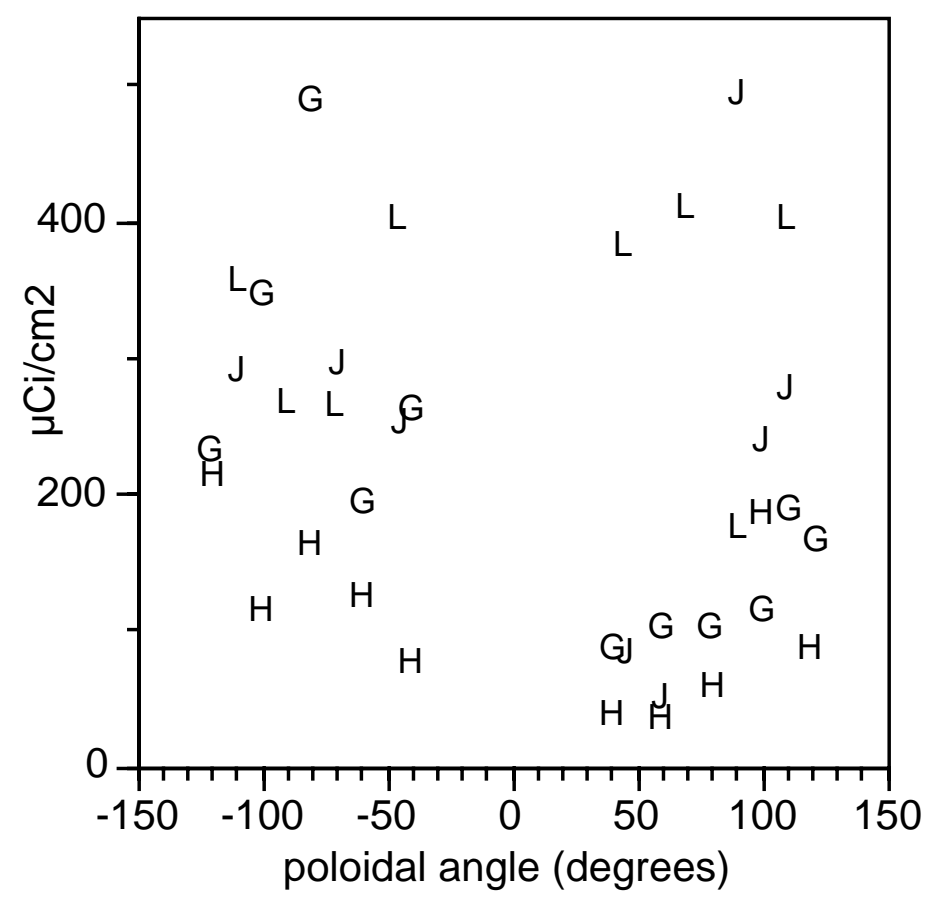

Fig. 2 Surface tritium measured by an open wall ion chamber on the vacuum vessel surface in a poloidal ring at Bays G, H, J, L. '0' degrees corresponds to the outboard midplane. 


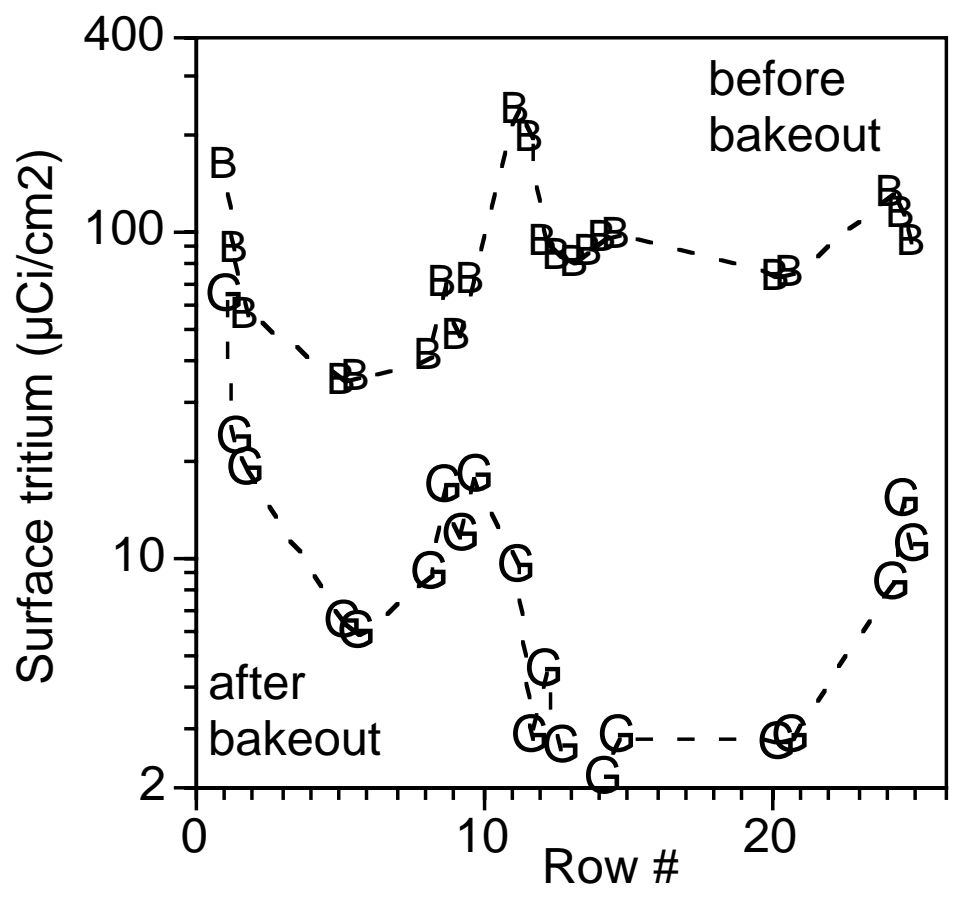

Fig. 3 Surface tritium measured on Bay $\mathrm{K}$ centerline before and after bakeout of selected tiles. The lines are intended as a visual aid. 


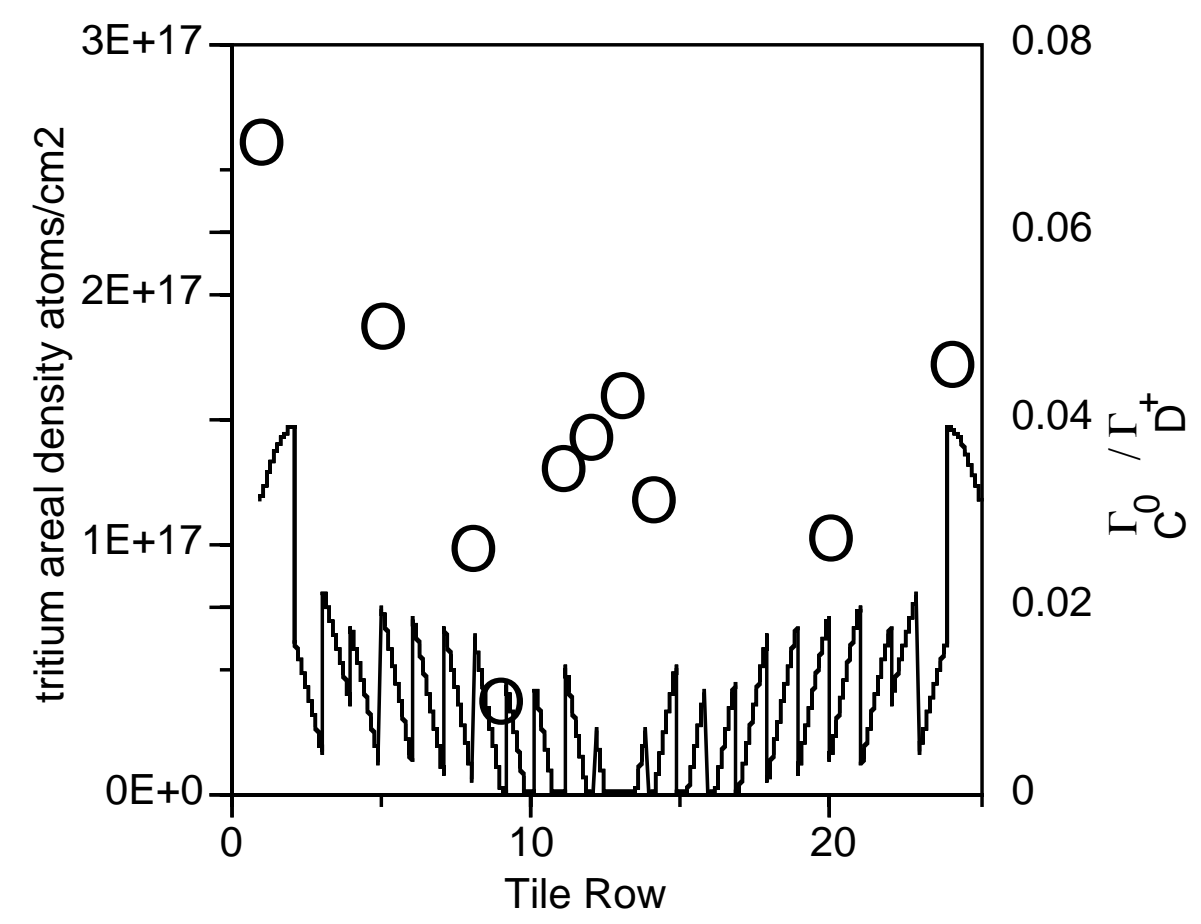

Figure 4. Areal density of tritium averaged over available tiles from each row (circles) and local effective sputtering yield distribution (emitted impurity flux / incident D+ flux) from Fig. 3a of Ref [29] 


\section{References}

[1] G. Federici et al., J. Nucl. Mater. 266-269 (1999) 14.

[2] A. Gibson et. al., Phys. Plasmas., 5 (1998) 1839.

[3] R. J. Hawryluk, Reviews of Modern Physics.70, 537-587 Apr. 1998

[4] C. H. Skinner et al., J. Vac. Sci. Technol., A14 (1996) 3267.

[5] P. Andrew et al., Fusion Eng.\& Des. 47 (1999) 233.

[6] C. H. Skinner et al., J. Nucl. Mater. 241-243 (1997) 214.

[7] C. H. Skinner et al., in Fusion Technology (Proc. 20 ${ }^{\text {th }}$ Symp. Marseille, 1998), Vol 1 Association Euratom-CEA, Cadarache (1998) 153.

[8] D. Mueller, et al., in 17th IEEE/NPSS Symposium on Fusion Engineering, IEEE, Piscataway, NJ, USA (1998) (Proc. 17th IEEE/NPSS Symposium, San Diego, Oct. 6-10, 1997), vol.1 p.279.

[9] A. Nagy et al, in 17th IEEE/NPSS Symposium on Fusion Engineering, IEEE, Piscataway, NJ, USA (1998) (Proc. 17th IEEE/NPSS Symposium, San Diego, Oct. 6-10, 1997), vol.1 p.317.

[10] M. D. McSmith, G.D. Loesser and D. K. Owens, Fusion Tech. 26 (1994) 498.

[11] T. Q. Hua and J. N. Brooks, J. Nucl. Mater., 196-198 (1992) 514. Note corrected units for Figs 5 and 7 are $100 \AA / s$ (T.Q. Hua, personal communication).

[12] C. H. Skinner et al., Nucl. Fus. 39 (1999) 1081.

[13] C. H. Skinner, C. A. Gentile, and K. M. Young, Proceedings of the $18^{\text {th }}$ IEEE/NPSS Symposium on Fusion Engineering, Oct.25-29 1999 Albuquerque NM, p.89 IEEE, Piscataway, NJ, (1999). Note numbers in Fig. $5 \& 7$ should be corrected by factor x7.1.

[14] C. A. Gentile et al., these proceedings. 
[15] E. Perry et al., "Decontamination and Decommissioning of the Tokamak Fusion Test Reactor" Proceedings of the $18^{\text {th }}$ IEEE/NPSS Symposium on Fusion Engineering, Oct 25-29 Albuquerque, NM, p.97 IEEE, Piscataway, NJ, (1999).

[16] W. R. Wampler et al., J. Vac. Sci. Technol., A6 (1998) 2111.

[17] R.A. Causey, W. R. Wampler and D. Walsh, J. Nucl. Mater., 176\&177 (1990) 987.

[18] J.W. Davis and A. A. Haasz, J. Nucl. Mater., 266-269 (1999) 478.

[19] C. H. Skinner et al., Nucl. Fusion 39 (1999) 271, reported by W.R. Wampler.

[20] H. F. Dylla and K L. Wilson, (Eds) Tritium Retention in TFTR, Rep. PPPL-2523 Princeton Plasma Physics Lab. NJ.

[21] O. A. Griesbach and J. R. Stencel, "The PPPL Differential Atmospheric Tritium Sampler (DATS)," Proceedings of the $22^{\text {nd }}$ Midyear Symposium of the Health Physics Society, San Antonio, TX., Dec. 1988, 374-380.

[22] N. P. Kherani and W. T. Shymayda, Fus. Tech. 28 (1995).

[23] C. H. Skinner et al., Proceedings of the 17th IEEE/NPSS Symposium on Fusion Engineering, San Diego, October 6-10 1997, Vol.1 p.321, IEEE, Piscataway, NJ, (1998).

[24] K. A. McCarthy et al., Fusion Tech. 34 (1998) 728.

[25] J. Winter and G. Gebauer, J. Nucl. Mater., 266-269 (1999) 228.

[26] B. Patel et al., 'Radiological Properties of Tritiated Dusts and Flakes from the JET Tokamak" Proceedings of the $18^{\text {th }}$ IEEE/NPSS Symposium on Fusion Engineering, Oct 25-29 Albuquerque, NM, p.97 IEEE, Piscataway, NJ, (1999).

[27] P. H. LaMarche et al., in Fusion Technolology p. 1172, Elsevier, Amsterdam (1993).

[28] W. J. Carmack et al., Proceedings of the 5th Symposium on Fusion Nuclear Technology, ISFNT-5, 19-24 September 1999, Rome, ITALY.

[29] C. H. Skinner, J. T. Hogan et al., J. Nucl. Mater., 266-269 (1999) 940. 
The Princeton Plasma Physics Laboratory is operated by Princeton University under contract with the U.S. Department of Energy.

\author{
Information Services \\ Princeton Plasma Physics Laboratory \\ P.O. Box 451 \\ Princeton, NJ 08543
}

Phone: 609-243-2750

Fax: 609-243-2751

e-mail: pppl_info@pppl.gov

Internet Address: http://www.pppl.gov 